\title{
MOFs-Derived Nano-CuO Modified Electrode as a Sensor for Determination of Hydrazine Hydrate in Aqueous Medium
}

\author{
Yaqi Lu ${ }^{1,2}$, Dan $\mathrm{Wu}^{1}{ }^{1}$, Ziyin $\mathrm{Li}^{1}{ }^{1}$, Quanjie Lin ${ }^{1}$, Xiuling Ma ${ }^{1}{ }^{1 *}$, Zhangjing Zhang ${ }^{1}$ and \\ Shengchang Xiang ${ }^{1, *}$ \\ 1 Fujian Provincial Key Laboratory of Polymer Materials, College of Chemistry and Materials Science, \\ Fujian Normal University, 32 Shangsan Road, Fuzhou 350007, China; fjluyaqi@163.com (Y.L.); \\ lyxylyh@163.com (D.W.); lzyinann@163.com (Z.L.); linquanjie@hotmail.com (Q.L.); \\ zzhang@fjnu.edu.cn (Z.Z.) \\ 2 College of Chemistry and Materials Science, Longyan University, No.1 North Dongxiao Rd., \\ Longyan 364012, China \\ * Correspondence: xlma@fjnu.edu.cn (X.M.); scxiang@fjnu.edu.cn (S.X.)
}

Received: 21 November 2019; Accepted: 22 December 2019; Published: 24 December 2019

\begin{abstract}
It very important to be able to efficiently detect hydrazine hydrate in an aqueous medium due to its high toxicity. Here, we have proposed a new idea: to construct a sensor for the rapid determination of hydrazine hydrate based on the nano- $\mathrm{CuO}$ derived by controlled pyrolysis of HKUST-1 $\left[\mathrm{Cu}_{3}(\mathrm{BTC})_{2}\left(\mathrm{H}_{2} \mathrm{O}\right)_{3}\right]$. The as-prepared $\mathrm{CuO}$ at $400{ }^{\circ} \mathrm{C}$ possesses a uniform appearance with nano-structure via SEM images, and the nano-CuO- 400 has exhibited excellent electrocatalytic activity towards hydrazine oxidation. Amperometric $i-t$ curves shows the peak current as linearly proportional to the hydrazine concentration within 1.98-169.3 $\mu \mathrm{mol} \mathrm{L}^{-1}$ and $232-2096 \mu \mathrm{mol} \mathrm{L}^{-1}$ with the detection limit of $2.55 \times 10^{-8} \mathrm{~mol} \mathrm{~L}^{-1}$ and $7.01 \times 10^{-8} \mathrm{~mol} \mathrm{~L}^{-1}$, respectively. Moreover, the sensor constructed in the experiment shows good selectivities, and it is feasible to determining actual water samples.
\end{abstract}

Keywords: metal-organic frameworks; pyrolysis derivatives; electrochemical sensor; hydrazine hydrate

\section{Introduction}

Hydrazine hydrate, which is an important chemical raw material, is widely used as antioxidant, rocket propellant, preservative, insecticide, plant growth regulator, etc. [1]. However, it is highly toxic and a hydrazine content above $10 \mathrm{ppb}$ can induce steatosis, nausea, pulmonary edema, nasal irritation, DNA damage, temporary blindness and so on [2,3]. In addition, hydrazine hydrate has been listed as a carcinogen by the US Environmental Protection Agency [4]. Therefore, it is of great significance to detect hydrazine hydrate efficiently and sensitively.

Various methods for detecting hydrazine hydrate have already been established, such as spectrophotometry, electrochemiluminescence, GC-MS, and high-performance liquid chromatography (HPLC) [5-9], which display excellent repeatability and sensitivity. However, they may be inconvenient due to the high-cost and time-consuming running. Therefore, it is worth developing a simple and practical approach for determining the trace levels of hydrazine in water. Electrochemical techniques offer portable, quick, and economical methodologies, which has attracted the attention of researchers [10]. As hydrazine has strong reducibility, it is easy to oxidize on the surface of electrodes, and the electrochemical determination of hydrazine hydrate has been proven to be a feasible detection method [11]. To improve the sensitivity and reproducibility of hydrazine's reaction on electrodes, 
some functionalized nanomaterials have been used for the construction of hydrazine hydrate chemical sensors [12-17]. Although the above method enhances the electrochemical reaction of hydrazine, most are noble metal nanoparticles, which limits the application in reality. Cupric oxide, a non-precious metal oxide, has been widely used in sensors due to its low cost and good catalytic ability [18-20], and it has also been reported as useful for detecting hydrazine hydrate [21-25]. Further study on the sensor is still required in order to accelerate development of an effective method for detecting hydrazine hydrate.

Metal-organic frameworks (MOFs), which have attracted extensive attention in recent years, are a kind of inorganic-organic hybrid materials with extensive applications including gas adsorption and separation, catalysis, luminescence, electrode materials, etc. [26-30]. Porous MOF-based sensors were also developed [11]. However, most MOFs are unstable in a water phase, so it is hard to apply them directly to electrochemical measurement in aqueous environment. Due to the homogeneity of MOFs, the metal and organic ligands in MOFs can be transformed into derivatives with uniform structure and stable chemical properties under certain conditions, which attracted considerable attentions, especially in electrochemistry application [31-33].

In this study, instead of noble metal nanoparticles, the nano-CuO derived from the pyrolysis of HKUST-1, which is one of the first reported MOFs, was used to construct the hydrazine hydrate sensor (shown in Figure 1). HKUST-1 $\left[\mathrm{Cu}_{3}(\mathrm{BTC})_{2}\left(\mathrm{H}_{2} \mathrm{O}\right)_{3}\right]$ was chosen as the template for the pyrolysis derivatives because its skeleton contains coordination unsaturated metal $\mathrm{Cu}$ (II) and it easily obtains nano- $\mathrm{CuO}$. Additionally, it has been discovered that the structures and electrocatalytic performances of the materials may be controlled by the pyrolysis temperature. The response of hydrazine hydrate in the nano- $\mathrm{CuO}-400$ sensor is superior to that of the $\mathrm{CuO}-300$ sensor, $\mathrm{CuO}-500$ sensor, or bulk-CuO sensor. Furthermore, the nano-CuO-400-coated electrode with a low detection limit of $2.55 \times 10^{-8} \mathrm{~mol} \mathrm{~L}^{-1}$ is approximately 63 times lower than that of the $\mathrm{CuO}$-hollow-spheres-coated one [24] and equal to the nano-copper oxide obtained by electrodeposition [26], in which is difficult to obtain a lot of stable nano-sized cupric oxide. These results might confirm that the nano- $\mathrm{CuO}$ derived from the pyrolysis of MOFs could effectively improve the detection limit of the hydrazine hydrate sensor in aqueous phase. In addition, based on $\mathrm{CuO}$ nanostructures possessing superior physical and chemical properties, they show promising applications in various fields, such as gas sensors, nanohybrid catalyst and so on [34-36]. We believe the as-prepared nano-CuO-400 should has potential applications in other electrocatalytic fields.

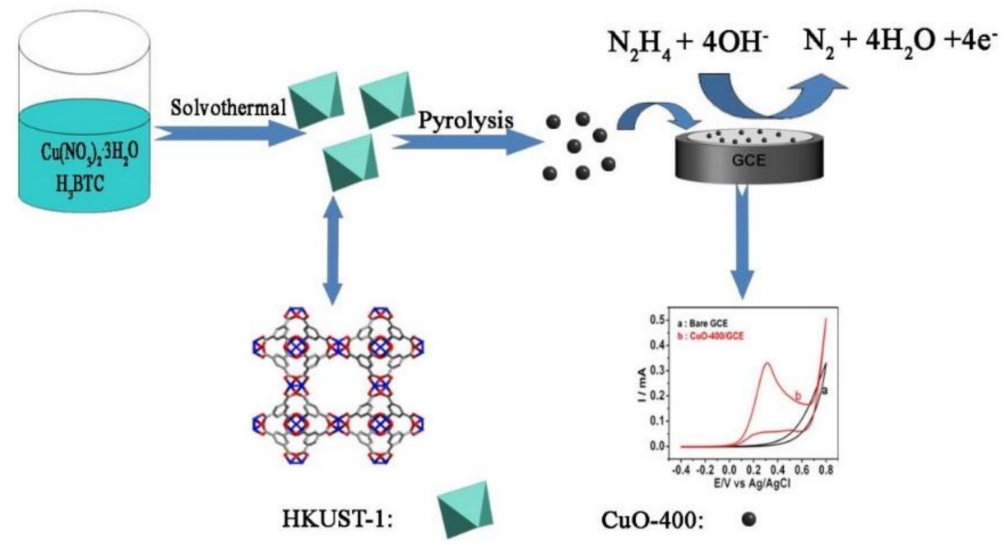

Figure 1. Illustration of the fabrication of nano-CuO sensor for hydrazine hydrate.

\section{Materials and Methods}

\subsection{Instruments and Reagents}

Powder X-ray diffraction (PXRD) was performed over the $2 \theta$ range of $5^{\circ}-30^{\circ}$ or $5^{\circ}-80^{\circ}$ (MiniFlex II Xpert power diffractometer equipped with a Cu-sealed tube at $40 \mathrm{kV}$ and $40 \mathrm{~mA}$, Rigaku, Woodlands, 
TX, USA). Fourier transform infrared spectra (FTIR, $\mathrm{KBr}$ pellets) were recorded in the range of $400 \sim 4000 \mathrm{~cm}^{-1}$ on a 5700 FT-IR spectrometer (Thermo Nicolet, Austin, USA). Thermal gravimetric analysis (TGA) curves were obtained from 30 to $600{ }^{\circ} \mathrm{C}$ at the heating rate of $10{ }^{\circ} \mathrm{C} / \mathrm{min}$ under nitrogen atmosphere by using a TGA/STDA 851 thermal analyzer (Mettler, Zurich, Switzerland). The morphology of the products was characterized with a S-4800 scanning electron microscope (SEM, Hitachi, Tokyo, Japan). Electrochemical measurements were conducted on an electrochemical workstation (CHI660E, Shanghai Chenhua Apparatus Company, Shanghai, China). Copper nitrate hydrate $\left(\mathrm{Cu}\left(\mathrm{NO}_{3}\right) 2 \cdot 3 \mathrm{H}_{2} \mathrm{O}\right), \mathrm{N}, \mathrm{N}$-dimethyl-formamide (DMF), acetone, sodium hydroxide $(\mathrm{NaOH}$, $96 \%)$ and hydrazine hydratex $\left(\mathrm{N}_{2} \mathrm{H}_{4} \cdot \mathrm{H}_{2} \mathrm{O}\right)$ were purchased from Sinopharm Chemical Reagent Co., Ltd. (Shanghai, China). 1,3,5-Benzenetricarboxylic acid (99\%, H3BTC) was purchased from Aladdin (Shanghai, China). All the other chemicals were analytical reagent grade or better.

\subsection{Preparation of $\mathrm{Nano}-\mathrm{CuO}$}

The quartz boat was covered with the prepared HKUST-1 (see the Supplementary Materials). The heat treatment was carried out under the air condition in a tubular furnace. HKUST-1 were heated to $400{ }^{\circ} \mathrm{C}$ at a rate of $5{ }^{\circ} \mathrm{C} / \mathrm{min}$, and at $400{ }^{\circ} \mathrm{C}$ for $2 \mathrm{~h}$, then naturally cooled to room temperature. The product is named CuO-400. In order to study the effect of heat treatment temperature on the product, with other conditions unchanged, the products named $\mathrm{CuO}-300$ and $\mathrm{CuO}-500$ were obtained by heat treatment at $300{ }^{\circ} \mathrm{C}$ and $500{ }^{\circ} \mathrm{C}$, respectively.

\subsection{Fabrication of Nano-CuO Sensor}

A glassy carbon electrode (GCE) was polished carefully with $0.3 \mathrm{~cm}$ and $0.05 \mathrm{~cm}$ alumina slurry, and thoroughly rinsed ultrasonically with acetone and water for $2 \mathrm{~min}$ in turn, then dried under infrared light. Took $5 \mathrm{mg} \mathrm{CuO}-400$ into $1 \mathrm{~mL}$ ethanol. After improving the uniformity by the ultrasonic dispersion, added $10 \mu \mathrm{L} 5 \mathrm{mg} / \mathrm{mL} \mathrm{CuO-400} \mathrm{suspension} \mathrm{on} \mathrm{the} \mathrm{GCE} \mathrm{surface} \mathrm{using} \mathrm{drop-casting} \mathrm{method.}$ Then dried the electrode by infrared light. Finally, $5 \mu \mathrm{L}$ of $0.5 \%$ Nafion droplets were applied to the surface of the electrode, and CuO-400/GCE was obtained. The preparation of CuO-300/GCE or CuO-500/GCE was done following the above steps.

\subsection{Electrochemical Detection}

The detection was conducted by a three-electrode system in which a modified GCE ( $3.0 \mathrm{~mm}$ in diameter), $\mathrm{Ag} / \mathrm{AgCl}$ electrode with saturated $\mathrm{KCl}$ and a platinum electrode were used as working electrode, reference electrode and the counter electrode, respectively. Cyclic voltammetry (CV) was performed in the static solution, and the potential range was $-0.4 \mathrm{~V}$ to $0.8 \mathrm{~V}$. The amperometric $i-t$ curve was obtained through dynamic tests that required constant stirring of the solution. The supporting electrolyte used was $0.1 \mathrm{~mol} \mathrm{~L}^{-1} \mathrm{NaOH}$. Before each test, the solution was flushed with nitrogen for $15 \mathrm{~min}$ to ensure that there was no oxygen interference in the solution.

Water samples collected from the Minjang river (in Fujian, China) were filtered three times before analysis. Different amounts of hydrazine hydrate were added to the water samples which were then analyzed under optimized conditions using the standard addition method.

\section{Results and Discussion}

\subsection{Characterization of HKUST-1}

PXRD was used to evaluate whether the synthesized compound (HKUST-1) was a pure phase. Figure S1 (in the Supplementary Material) showed the pattern of the synthesized HKUST-1, which was consistent with the simulated PXRD pattern of HKUST-1 reported previously. The results showed that the synthesized HKUST-1 is pure. The FT-IR spectra of HKUST-1 was shown in Figure S2a in the Supplementary Material. The characteristic bands at $1643 \mathrm{~cm}^{-1}$ and $1372 \mathrm{~cm}^{-1}$ are attributed to the asymmetric stretching vibration and symmetric stretching vibration of the carboxyl groups on 
trimesic acid, respectively. The broad band at about $3430 \mathrm{~cm}^{-1}$ could be assigned to $\mathrm{O}-\mathrm{H}$ stretching vibrations. Meanwhile, the thermal behavior of HKUST-1 powders was investigated by TGA technique which can provide the base for the pyrolysis characteristics of HKUST-1, shown in Figure S2b in the Supplementary Material. Loss of weight before $100^{\circ} \mathrm{C}$ was caused by water adsorbed on the pore of samples, while the loss of the weight at $210^{\circ} \mathrm{C}-337^{\circ} \mathrm{C}$ was related to the removal of the DMF solvent and after $337^{\circ} \mathrm{C}$, it was ascribed to the decomposition of HKUST-1. Thereby, $300{ }^{\circ} \mathrm{C}, 400{ }^{\circ} \mathrm{C}$ and $500{ }^{\circ} \mathrm{C}$ were chosen as the pyrolysis temperatures for obtaining nano- $\mathrm{CuO}$.

\subsection{Analysis of Nano-CuO}

The PXRD patterns of the nano-CuO derived by the pyrolysis of HKUST-1 at the different heat treatment temperatures are shown in Figure 2A. The diffraction peaks of $\mathrm{CuO}-400$ or $\mathrm{CuO}-500$ at $32.5^{\circ}$, $35.5^{\circ}, 38.7^{\circ}, 48.8^{\circ}, 53.4^{\circ}, 58.3^{\circ}, 61.6^{\circ}, 66.3^{\circ}, 68.0^{\circ}, 72.3^{\circ}$ and $74.9^{\circ}$ matched perfectly with the peaks of the card of JCPDS No. 41-0254, which were found to be in agreement with the (110), (002), (111/200), (-202), (020), (202), (-113), (-311), (220), (311) and (-222) facet of CuO crystal [37], respectively. Meanwhile, $\mathrm{CuO}-300$ didn't show all the feature peaks because of incomplete decomposition of HKUST-1 at $300{ }^{\circ} \mathrm{C}$. What's more, the influence of the different pyrolysis temperature on the electrochemical property of hydrazine hydrate on nano-CuO/GCE were further examined by the CV in $0.1 \mathrm{~mol} \mathrm{~L}^{-1} \mathrm{NaOH}^{-}$ solutions with $1 \mathrm{mmol} \mathrm{L}^{-1}$ hydrazine hydrate, shown in Figure $2 \mathrm{~B}$. The highest peak current as well as good shape of hydrazine hydrate were displayed on the electrode modified with CuO-400. Although the $\mathrm{CuO}-400$ and $\mathrm{CuO}-500$ presented the same diffraction pattern, their electrochemical performance were different. These indicated that different heat treatment temperature could affect the properties of materials. Therefore, $\mathrm{CuO}-400$ was selected as the main subject in the following section.
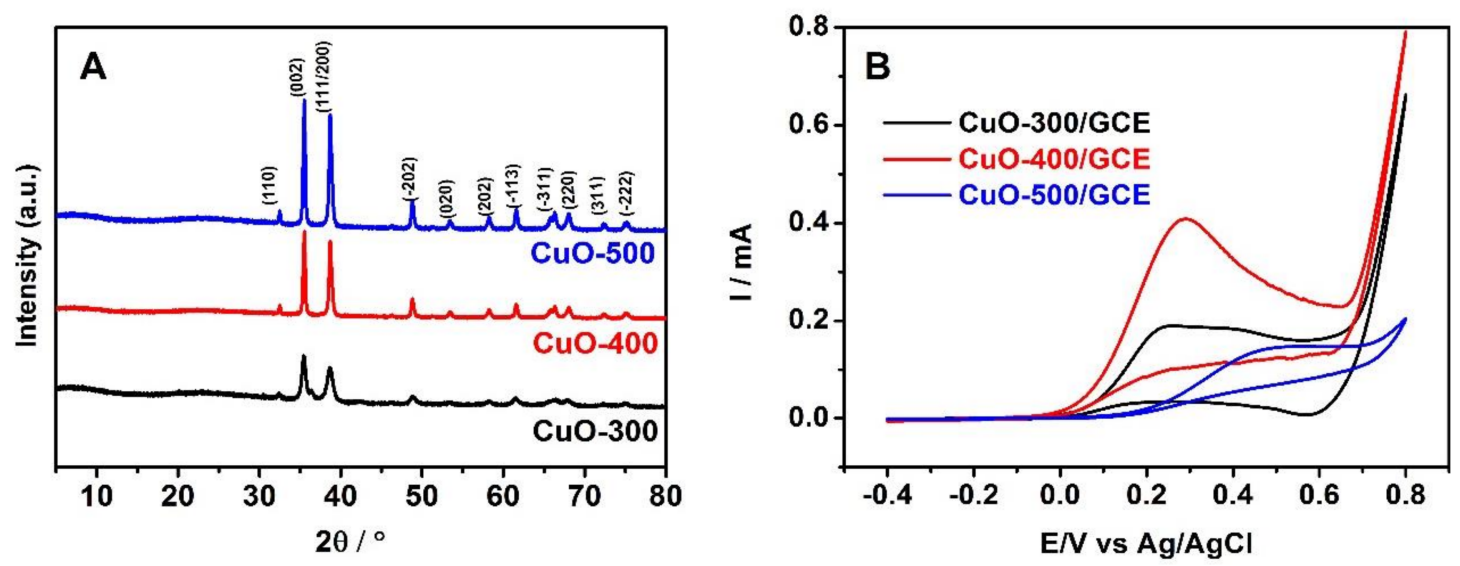

Figure 2. The PXRD patterns (A) and CV curves (B) of nano-CuO obtained at different temperatures.

SEM studies were further conducted to investigate microstructure morphology of HKUST-I and its pyrolysis $\mathrm{CuO}-400$, as shown in Figure 3. It can be seen that the most of HKUST-I is octahedral morphology and has smooth surface as well as good dispersion, while CuO-400 lost the original appearance of HKUST-I and became irregular. Meanwhile, its particle size is less than $500 \mathrm{~nm}$. 

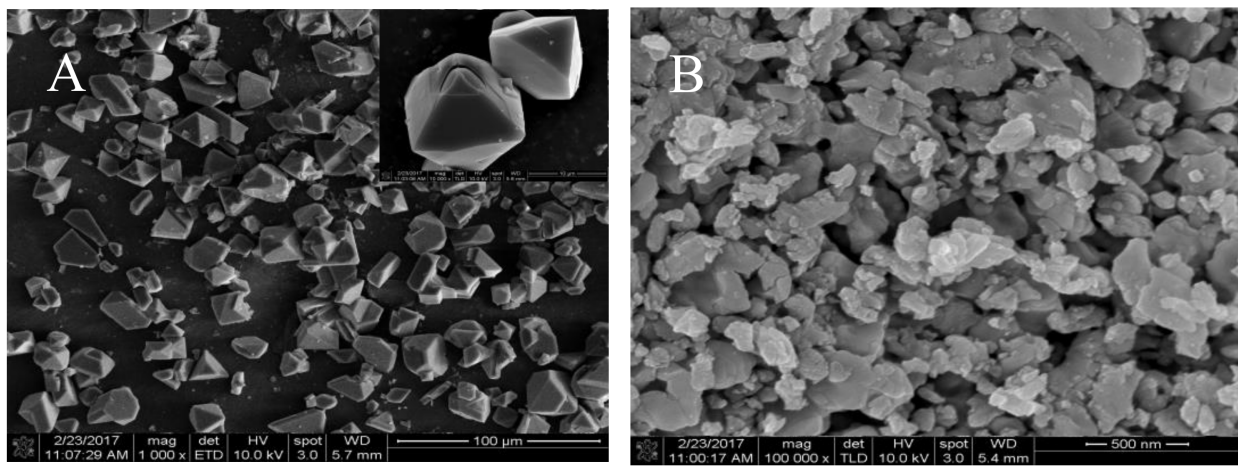

Figure 3. SEM images of HKUST-1(A) and CuO-400(B).

\subsection{Optimization of the Experimental Conditions}

To get the optimal conditions for detecting hydrazine, $\mathrm{CV}$ was performed in the following sections by using nano-CuO-400/GCE. The effect of the drop-coating doses of nano-CuO-400 was performed with different doses of nano-CuO-400 coating on GCE, shown in Figure 4A. From $6 \mu \mathrm{L}$ to $10 \mu \mathrm{L}$, the responses to $1 \mathrm{mmol} \cdot \mathrm{L}^{-1}$ hydrazine hydrate increased dramatically. After the dose was increased to $12 \mu \mathrm{L}$, the responses gradually decreased. Therefore, the drop amount of nano-CuO-400 was selected to be $10 \mu \mathrm{L}$ in this study. Also, the effect of the concentration of $\mathrm{NaOH}$ solution was studied, as shown in Figure 4B. The peak current of hydrazine increased when increasing $\mathrm{NaOH}$ concentration $\left(0.05 \mathrm{~mol} \cdot \mathrm{L}^{-1}-0.1 \mathrm{~mol} \cdot \mathrm{L}^{-1}\right)$, and the oxidation peak potential showed negative shift. After increasing the concentration of $\mathrm{NaOH}$ (over $0.1 \mathrm{~mol} \cdot \mathrm{L}^{-1}$ ), the oxidation peak current decreased, and the oxidation peak potential shifted positively. A more negative oxidation peak potential and higher peak current may be beneficial for faster electron-transfer reaction and sensitive detection, respectively. Thus, $0.1 \mathrm{~mol} \cdot \mathrm{L}^{-1} \mathrm{NaOH}$ was considered the appropriate concentration for investigating the electrochemical activity of hydrazine. Additionally, the oxidative peak potential of hydrazine shifted with the changes of the $\mathrm{NaOH}$ concentration, which indicated that the rate-determining step is the formation of the $\left[\mathrm{HO}-\mathrm{H}_{2} \mathrm{NNH}_{2}-\mathrm{OH}\right]^{2-}$ ion [26].
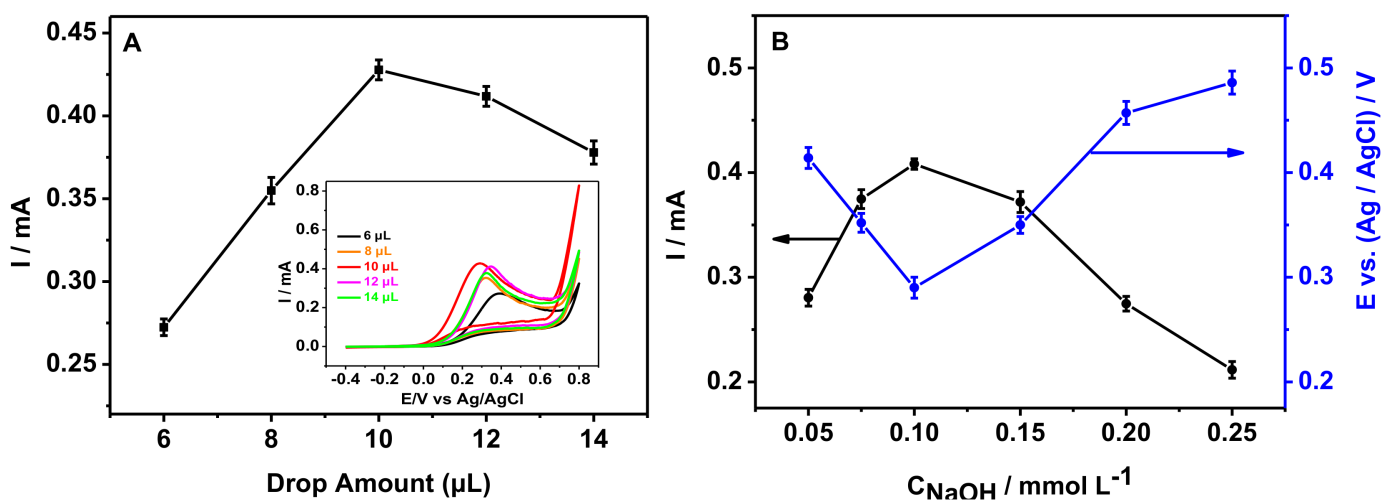

Figure 4. The effect of the drop amount of nano-CuO-400 (A)inset is the CV curves and the concentration of $\mathrm{NaOH}(\mathbf{B})$ on the electrochemical behavior of hydrazine.

\subsection{Electrochemical Properties of Nano-CuO-400/GCE Sensor}

To analyze the charge transfer resistance of the nano-CuO/GCE, the electrochemical impedance spectroscopy (EIS) was conducted in this work, shown in Figure 5A. Nano-CuO-400/GCE showed a lower resistance $(\sim 100 \Omega)$ than bare GCE $(\sim 370 \Omega)$ in $5.0 \mathrm{mmol} \cdot \mathrm{L}^{-1}\left[\mathrm{Fe}(\mathrm{CN})_{6}\right]^{3 / 4-}$ with $0.1 \mathrm{~mol} \cdot \mathrm{L}^{-1}$ $\mathrm{KCl}$, which suggested that electron transfer at the nano-CuO-400/GCE is faster than that the bare GCE. Figure 5B shows the effect of scan rates (v) on the peak current (I) in $0.1 \mathrm{~mol} \cdot \mathrm{L}^{-1} \mathrm{NaOH}$ containing $1 \mathrm{mmol} \cdot \mathrm{L}^{-1}$ hydrazine. The peak current increased at the scan rate of $20 \mathrm{mV} / \mathrm{s} \sim 400 \mathrm{mV} / \mathrm{s}$, 
and a linear relationship that Ip $=0.043 v^{1 / 2}+0.1104\left(R^{2}=0.998\right.$, inset $)$ between $\mathrm{I}$ and $v^{1 / 2}$ was obtained. This result indicates that the oxidation process of hydrazine hydrate at the sensor is a diffusion-controlling behavior.
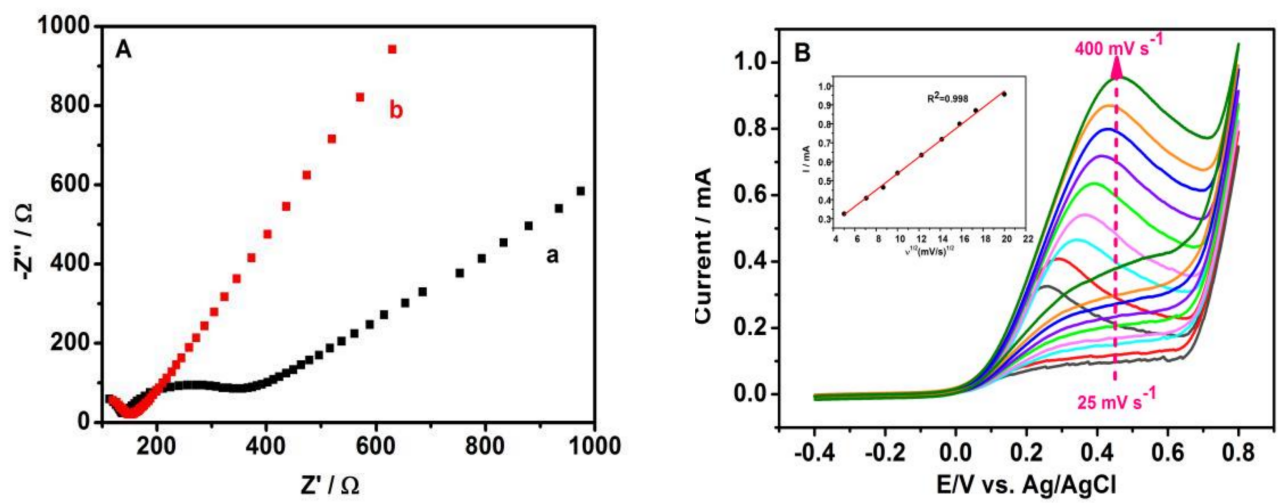

Figure 5. The Nyquist diagrams (A) of bare GCE (a) and CuO-400/GCE(b), and CV curves (B) of CuO-400/GCE at different scan rates (inset shows the linear relation of $I \sim v^{1 / 2}$ ).

In addition, HKUST- 1 and bulk-CuO were selected as references for controlled trials. The results of $\mathrm{CV}$ for different materials at the scan rate of $50 \mathrm{mV} / \mathrm{s}$ are shown in Figure 6A-D.
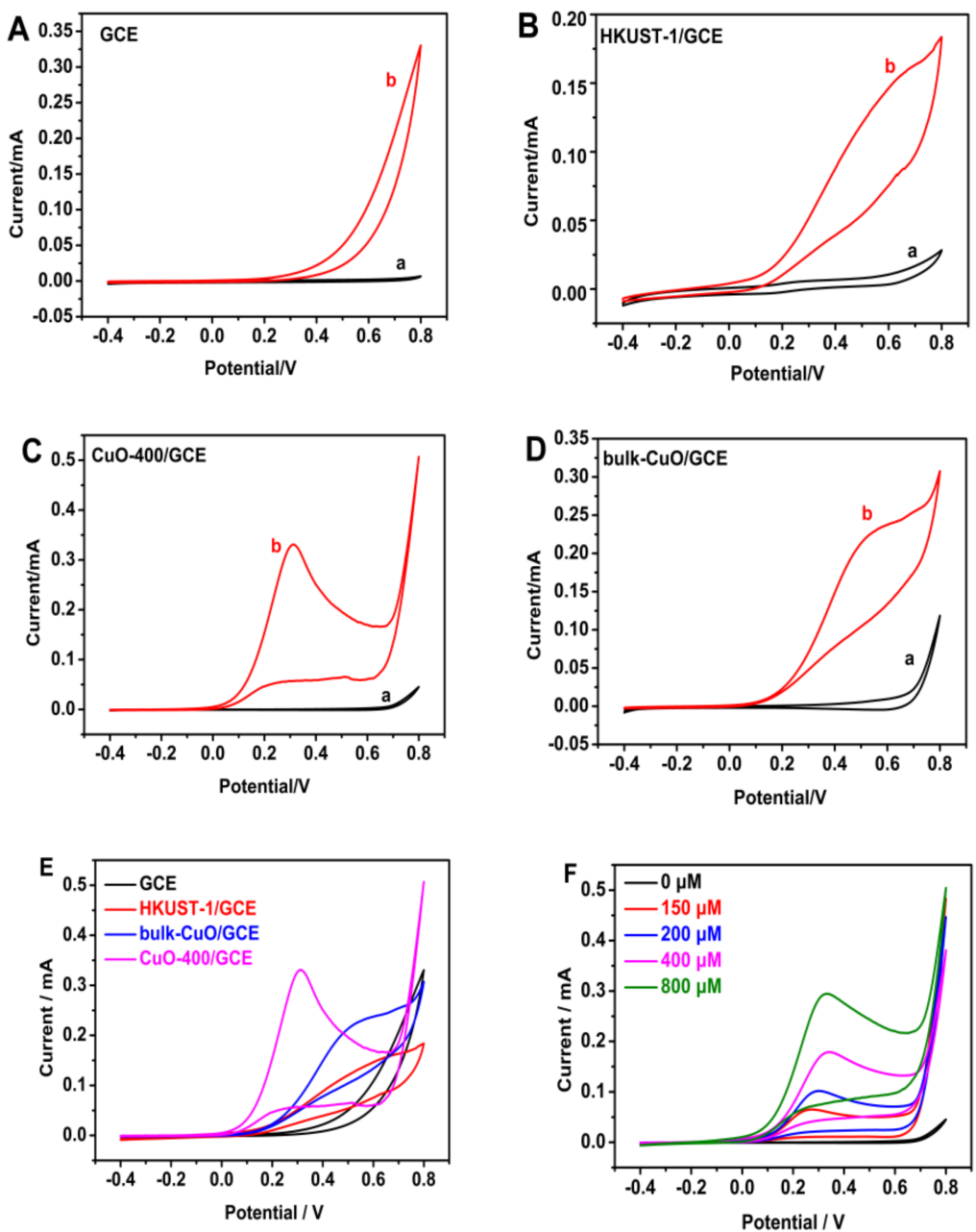

Figure 6. $\mathrm{CV}$ curves for different electrodes (A-E) and different concentrations of hydrazine hydrate at CuO-400/GCE (F). 
There are no detectable peak in $0.1 \mathrm{~mol} \cdot \mathrm{L}^{-1} \mathrm{NaOH}$ solution (curve a) at all electrodes. When the solution containing $1 \mathrm{~mol} \cdot \mathrm{L}^{-1}$ hydrazine hydrate (curve b), different electrodes showed different results. The oxidation peak of hydrazine hydrate was not observed on the bare GCE in Figure 6A (curve b), indicating that the GCE has no catalytic activity to hydrazine hydrate. To the HKUST-1/GCE in Figure $6 \mathrm{~B}$ (curve b), there was a wide, weak and irreversible oxidation peak at $\sim 0.6 \mathrm{~V}$, while, a sharp and strong oxidation peak appears at $\sim 0.31 \mathrm{~V}$ on the $\mathrm{CuO}-400 / \mathrm{GCE}$ in Figure $6 \mathrm{C}$ (curve b). Additionally, the hydrazine hydrate showed an irreversible oxidation peak at $\sim 0.5 \mathrm{~V}$ for the purchase of nano-CuO (Figure 6D, curve b).

Comparing CuO-400/GCE, bulk-CuO/GCE and HKUST-1/GCE in Figure 6E, the catalytic oxidation at the CuO-400/GCE are much sharper and shift to a negative-going direction, which reflects a faster electron-transfer reaction on the CuO-400/GCE owing to the high catalytic effect of the characteristic of nano-CuO. In addition, $\mathrm{CV}$ was performed to determine hydrazine hydrate after the $\mathrm{CuO}-400 / \mathrm{GCE}$ sensor was immersed in solutions containing hydrazine hydrate of different concentration (0, 150, 200, 400, $800 \mu \mathrm{mol} \cdot \mathrm{L}^{-1}$ ), shown in Figure $6 \mathrm{~F}$. It can be found that the oxidation peak current increases with the increase of hydrazine hydrate concentration in the range of $0 \sim 800 \mu \mathrm{mol} \cdot \mathrm{L}^{-1}$. This proved that the nano-CuO-400 shows a good electrocatalyst to hydrazine hydrate.

\subsection{The Detection Limit of the Sensor for Hydrazine Hydrate}

In order to further evaluate the electrochemical sensing for hydrazine hydrate on the CuO-400/GCE sensor, amperometric $i-t$ curves were performed at an applied potential of $0.31 \mathrm{~V}$ with the successive addition of hydrazine ranging from $1.98 \mu \mathrm{mol} \cdot \mathrm{L}^{-1}$ to $2096 \mu \mathrm{mol} \cdot \mathrm{L}^{-1}$ in $0.1 \mathrm{~mol} \cdot \mathrm{L}^{-1} \mathrm{NaOH}$ by stirring. As shown in Figure 7a, the peak current gradually increased with the increase of the hydrazine hydrate concentrations. It appeared to platform at every concentration stage and reached a stable current for no more than $5 \mathrm{~s}$, indicating that the sensor has a short response time. Figure $7 \mathrm{~b}$ shows the peak current as linearly proportional to the hydrazine concentration in the range of $1.98 \mu \mathrm{mol} \cdot \mathrm{L}^{-1}$ to $169.3 \mu \mathrm{mol} \cdot \mathrm{L}^{-1}$ with the linear regression equation: $\mathrm{I}(\mu \mathrm{A})=0.08902 \mathrm{C}(\mu \mathrm{mol} \mathrm{L}-1)+0.0401\left(\mathrm{R}^{2}=0.984\right)$ and a sensitivity of $89.02 \mu \mathrm{A}\left(\mathrm{mmol} \cdot \mathrm{L}^{-1}\right)^{-1}$, as well as $232 \mu \mathrm{mol} \cdot \mathrm{L}^{-1}$ to $2096 \mu \mathrm{mol} \cdot \mathrm{L}^{-1}$ with the linear regression equation: $\mathrm{I}(\mu \mathrm{A})=0.03720 \mathrm{C}(\mu \mathrm{mol} \mathrm{L}-1)+7.724\left(\mathrm{R}^{2}=0.978\right)$ and a sensitivity of $37.20 \mu \mathrm{A}$ $\left(\mathrm{mmol} \cdot \mathrm{L}^{-1}\right)^{-1}$, respectively.
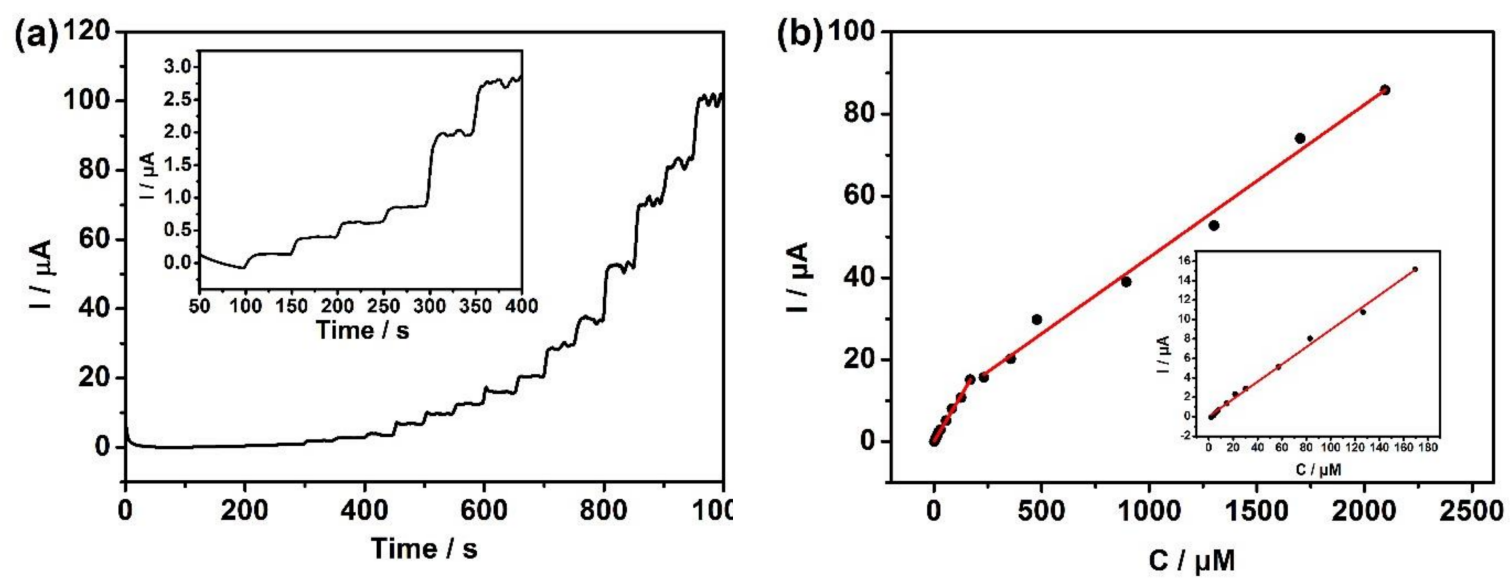

Figure 7. (a) is the amperometric $i$ - $t$ curve of the $\mathrm{CuO}-400 / \mathrm{GCE}$ and (b) shows the linear relation of I C hydrazine.

According to the equation recommended by IUPAC, the limit of detection (LOD) was estimated to be $2.55 \times 10^{-8} \mathrm{~mol} \cdot \mathrm{L}^{-1}$ and $7.01 \times 10^{-8} \mathrm{~mol} \mathrm{~L}-1$, which outperformed the sensor constructed by $\mathrm{Pt}-\mathrm{TiO}_{2}$ [16], Pd/carbon black [13], CuS-RGO [38], and $\mathrm{CuO}$ hollow spheres [24] and equal to the nano-copper oxide obtained via electrodepositing [26] (shown in Table S1). Based on the lower LOD 
with the wider linear range and the following content, we thought it was a feasible method for the determination of hydrazine hydrate in aqueous solution.

\subsection{Anti-Interference Capability, Reproducibility, Recovery and Stability of the Sensor}

To determine hydrazine in actual water samples by using the sensor, it is necessary to carry out anti-interference studies by adding hydrazine hydrate and certain substances to the $0.1 \mathrm{~mol} \cdot \mathrm{L}^{-1} \mathrm{NaOH}$ solution in sequence. The concentration of the substances was 100 times of that of hydrazine hydrate, which was $50 \mu \mathrm{mol} \cdot \mathrm{L}^{-1}$. As shown in Figure 8, the current appeared to have an obvious response to the addition of hydrazine, and there was a slight change of current when a NaNO2 solution was added; current fluctuation was almost restored to its original position after adding $\mathrm{KCl}, \mathrm{Na} 2 \mathrm{SO} 4$, $\mathrm{NaAc}$, and $\mathrm{NaBr}$ solutions. Althouth the working principle of the sensor is based on oxidation of hydrazine, the adding of oxidizable component- $\mathrm{NaNO}_{2}$ had little effect. These results indicated that the determination of hydrazine were unimpaired by the used interferent with/without oxidizable component, which showed that the proposed sensor possesses fairly good selectivity.

For evaluating the reproducibility of the constructed sensor, five parallel modified electrodes were prepared using the same method and were investigated in the presence of $5.0 \times 10^{-4} \mathrm{~mol} \cdot \mathrm{L}^{-1}$ hydrazine hydrate. The experimental results showed a relative standard deviation (RSD) of $3.23 \%$, revealing the sensor with good reproducibility. Also, the sensor recovery was conducted as follow: after use, rinsing thoroughly under running water for $2 \mathrm{~min}$, then determining whether it returns to the previous current value by CV. The current value drops slightly after using it five times. The stability in aqueous medium of the modified electrode was studied by storing it in aqueous solution at $4{ }^{\circ} \mathrm{C}$ and recording the CV daily. The change of current wasn't obvious for a week. Two weeks later, a decrease of the current's response (about $9.6 \%$ ) for $5.0 \times 10^{-4} \mathrm{~mol} \cdot \mathrm{L}^{-1}$ hydrazine was detected, which appears as good stability in aqueous medium.

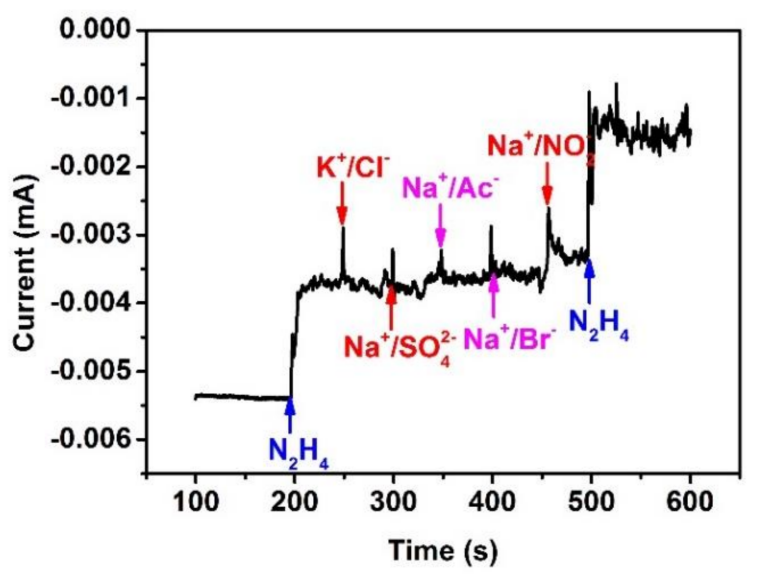

Figure 8. The response to the addition of hydrazine as well as interferent.

\subsection{Applications to the Water Samples}

To assess the feasibility of the nano-CuO-400/GCE sensor, it was applied to analysing the water samples. The spiked recovery experiments were conducted as the standard addition method, as follow: after adding known concentrations of hydrazine into water samples (added as $\mathrm{Ca}$ ), determining the concentration of hydrazine (added as $\mathrm{Cd}$ ) in water samples by the constructed sensor based on the above linear equation $(\mathrm{I}=0.08902 \mathrm{C}+0.0401$ or $\mathrm{I}=0.0372 \mathrm{C}+7.724)$, and $\mathrm{Ca}$ is divided by $\mathrm{Cd}$ for the recoveries. The amperometric response of spiked sample and the results were shown in Figure $\mathrm{S} 3$ and Table S2, respectively. The recovery rates were between $98.7 \%$ and $103.2 \%$, and the RSDs were less than $4 \%$, which reveals good accuracy and practicability of the proposed method. It shows the potential application to determine hydrazine hydrate in the water samples. 


\section{Conclusions}

This work developed an electrochemical sensor for the rapid determination of hydrazine hydrate based on nano-CuO derived from the pyrolysis of HKUST- 1 at $400{ }^{\circ} \mathrm{C}$. The nano-CuO-400 exhibited good electrochemical properties to hydrazine hydrate in $0.1 \mathrm{~mol} \cdot \mathrm{L}^{-1} \mathrm{NaOH}$ solution. The current increased linearly with the increase of the concentration of hydrazine within $1.98-169.3 \mu \mathrm{mol} \cdot \mathrm{L}^{-1}$ and $232-2096 \mu \mathrm{mol} \cdot \mathrm{L}^{-1}$ with a low detection limit of $2.55 \times 10^{-8} \mathrm{~mol} \cdot \mathrm{L}^{-1}$ and $7.01 \times 10^{-8} \mathrm{~mol} \cdot \mathrm{L}^{-1}$, respectively. In addition, it is possible to determine actual water samples by using this sensor. In sum, our work demonstrated that it is an option of monitoring hydrazine in aqueous phase.

\section{Data Availability}

In the article and its Supplementary Materials, all the information including raw data were shown.

Supplementary Materials: The following are available online at http://www.mdpi.com/1424-8220/20/1/140/s1. As Supplementary Materials, Synthesis of HKUST-1, Figures S1 and S2, and Tables S1 and S2 were included.

Author Contributions: S.X. conceived and designed the experiments; Y.L. and D.W. performed the experiments; Y.L. and X.M. wrote the paper; D.W., Z.L. and Q.L. analyzed the data; Z.Z. contributed reagents/materials/analysis tools. All authors have read and agreed to the published version of the manuscript.

Funding: The authors acknowledge the National Natural Science Foundation of China (21673039) and Natural Science Foundation of Fujian Province (2018J07001).

Conflicts of Interest: There are no conflict of interest in this manuscript.

\section{References}

1. Ragnarsson, U. Synthetic methodology for alkyl substituted hydrazines. Chem. Soc. Rev. 2001, 30, $205-213$. [CrossRef]

2. Prathap, M.A.; Anuraj, V.; Satpati, B.; Srivastava, R. Facile preparation of $\mathrm{Ni}(\mathrm{OH})_{2}-\mathrm{MnO}_{2}$ hybrid material and its application in the electrocatalytic oxidation of hydrazine. J. Hazard. Mater. 2013, 262, 766-774. [CrossRef] [PubMed]

3. Zelnick, S.D.; Mattie, D.R.; Stepaniak, P.C. Occupational exposure to hydrazines: Treatment of acute central nervous system toxicity. Aviat. Spaceenviron. Med. 2003, 74, 1285-1291.

4. Sun, M.; Guo, J.; Yang, Q.; Xiao, N.; Li, Y. A new fluorescent and colorimetric sensor for hydrazine and its application in biological systems. J. Mater. Chem. B 2014, 2, 1846-1851. [CrossRef]

5. Afsharas, A.; Tsyrulneva, I.; Zaporozhets, O. Spectroscopic, visual test techniques and optical sensors for determination of hydrazine and its derivatives. Methods Objects Chem. Anal. 2015, 10, 97-107. [CrossRef]

6. Liu, F.; Li, W.; Li, F.; Sun, S. Determination of hydrazine hydrate based on electrochemiluminescence of $\mathrm{Ru}(\mathrm{bpy})_{3}{ }^{2+}$. Environ. Monit. Assess. 2013, 185, 4153-4158. [CrossRef] [PubMed]

7. Subramanian, S.; Narayanasastri, S.; Reddy, A.R.K. Single step derivatization with $\mathrm{CF}_{3}$ enone of thiophene at ambient temperature to determine propellant grade hydrazines: A study by GC and GC-MS. Analyst 2015, 140, 330-339. [CrossRef] [PubMed]

8. Oh, J.A.; Shin, H.S. Simple and sensitive determination of hydrazine in drinking water by ultra-high-performance liquid chromatography-tandem mass spectrometry after derivatization with naphthalene-2, 3-dialdehyde. J. Chromatogr. A 2015, 1395, 73-78. [CrossRef]

9. Li, G.; Liu, S.; Sun, Z.; Xia, L.; Chen, G.; You, J. A simple and sensitive HPLC method based on pre-column fluorescence labelling for multiple classes of plant growth regulator determination in food samples. Food Chem. 2015, 170, 123-130. [CrossRef]

10. Mani, V.; Huang, S.T.; Devasenathipathy, R.; Yang, T.C.K. Electropolymerization of cobalt tetraaminophthalocyanine at reduced graphene oxide for electrochemical determination of cysteine and hydrazine. RSC Adv. 2016, 6, 38463-38469. [CrossRef]

11. Helal, A.; Qamaruddin, M.; Aziz, M.A.; Shaikh, M.N.; Yamani, Z.H. MB-UiO-66-NH ${ }_{2}$ Metal-Organic Framework as Chromogenic and Fluorogenic Sensor for Hydrazine Hydrate in Aqueous Solution. ChemistrySelect 2017, 2, 7630-7636. [CrossRef] 
12. Panchompoo, J.; Aldous, L.; Downing, C.; Crossley, A.; Compton, R.G. Facile synthesis of Pd nanoparticle modified carbon black for electroanalysis: Application to the detection of hydrazine. Electroanalysis 2011, 23, 1568-1578. [CrossRef]

13. Haghighi, B.; Hamidi, H.; Bozorgzadeh, S. Sensitive and selective determination of hydrazine using glassy carbon electrode modified with Pd nanoparticles decorated multiwalled carbon nanotubes. Anal. Bioanal. Chem. 2010, 398, 1411-1416. [CrossRef] [PubMed]

14. Chang, G.; Luo, Y.; Lu, W.; Hu, J.; Liao, F.; Sun, X. Immobilization of Au nanoparticles on Au electrode for hydrazine detection: Using thiolated single-stranded DNA as a linker. Thin Solid Film 2011, 519, 6130-6134. [CrossRef]

15. Ding, Y.; Wang, Y.; Zhang, L.; Zhang, H.; Li, C.M.; Lei, Y. Preparation of $\mathrm{TiO}_{2}-\mathrm{Pt}$ hybrid nanofibers and their application for sensitive hydrazine detection. Nanoscale 2011, 3, 1149-1157. [CrossRef]

16. Kumar, S.; Bhanjana, G.; Dilbaghi, N.; Umar, A. Zinc oxide nanocones as potential scaffold for the fabrication of ultra-high sensitive hydrazine chemical sensor. Ceram. Int. 2015, 41,3101-3108. [CrossRef]

17. Umar, A.; Akhtar, M.S.; Al-Hajry, A.; Al-Assiri, M.S.; Dar, G.N.; Islam, M.S. Enhanced photocatalytic degradation of harmful dye and phenyl hydrazine chemical sensing using $\mathrm{ZnO}$ nanourchins. Chem. Eng. J. 2015, 262, 588-596. [CrossRef]

18. Zhang, S.; Zhang, G.; He, P.; Lei, W.; Dong, F.; Yang, D.; Suo, Z. Novel one-pot hydrothermal fabrication of cuprous oxide-attapulgite/grapheme for non-enzyme glucose sensing. Anal. Methods 2015, 7, 2747-2753. [CrossRef]

19. Gu, W.; Wang, M.; Mao, X.; Wang, Y.; Li, L.; Xia, W. A facile sensitive l-tyrosine electrochemical sensor based on a coupled $\mathrm{CuO} / \mathrm{Cu}_{2} \mathrm{O}$ nanoparticles and multi-walled carbon nanotubes nanocomposite film. Anal. Methods 2014, 7, 1313-1320. [CrossRef]

20. Luo, B.; Li, X.; Yang, J.; Li, X.; Xue, L.; Li, X.; Gu, J.; Wang, M.; Jiang, L. Non-enzymatic electrochemical sensors for the detection of hydrogen peroxide based on $\mathrm{Cu}_{2} \mathrm{O} / \mathrm{Cu}$ nanocomposites. Anal. Methods 2014, 6, 1114-1120. [CrossRef]

21. Le, W.Z.; Liu, Y.Q. Preparation of nano-copper oxide modified glassy carbon electrode by a novel film plating/potential cycling method and its characterization. Sens. Actuators B Chem. 2009, 141, 147-153. [CrossRef]

22. Rosca, V.; Koper, M.T.M. Electrocatalytic oxidation of hydrazine on platinum electrodes in alkaline solutions. Electrochim. Acta 2008, 53, 5199-5205. [CrossRef]

23. Khan, S.B.; Faisal, M.; Rahman, M.M. Highly sensitive and stable phenyl hydrazine chemical sensors based on $\mathrm{CuO}$ flower shapes and hollow spheres. New J. Chem. 2013, 37, 1098-1104. [CrossRef]

24. Zhao, Z.; Wang, Y.; Li, P.; Sang, S.; Zhang, W.; Hu, J.; Lian, K. A highly sensitive electrochemical sensor based on $\mathrm{Cu} / \mathrm{Cu}_{2} \mathrm{O} @$ carbon nanocomposite structures for hydrazine detection. Anal. Methods 2015, 7, 9040-9046. [CrossRef]

25. Yin, Z.; Liu, L.; Yang, Z. An amperometric sensor for hydrazine based on nano-copper oxide modified electrode. J. Solid State Electrochem. 2011, 15, 821-827. [CrossRef]

26. Zhang, J.P.; Zhang, Y.B.; Lin, J.B.; Chen, X.M. Metal azolate frameworks: From crystal engineering to functional materials. Chem. Rev. 2012, 112, 1001-1033. [CrossRef]

27. Li, Z.; Ye, Y.; Yao, Z.; Guo, J.; Lin, Q.; Zhang, J.; Zhang, Z.; Wei, F.; Xiang, S. An antiferromagnetic metalloring pyrazolate $(\mathrm{Pz})$ framework with $\left[\mathrm{Cu}_{12}\left(\mu_{2}-\mathrm{OH}\right)_{12}(\mathrm{Pz})_{12}\right]$ nodes for separation of $\mathrm{C}_{2} \mathrm{H}_{2} / \mathrm{CH}_{4}$ mixture. J. Mater. Chem. A 2018, 6, 19681-19688. [CrossRef]

28. Ye, Y.; Chen, S.; Chen, L.; Huang, J.; Ma, Z.; Li, Z.; Yao, Z.; Zhang, J.; Zhang, Z.; Xiang, S. Additive-induced supramolecular isomerism and enhancement of robustness in Co(II)-based MOFs for efficiently trapping acetylene from acetylene-containing mixtures. ACS Appl. Mater. Interfaces 2018, 10, 30912-30918. [CrossRef]

29. Ye, Y.; Chen, S.; Chen, L.; Huang, J.; Ma, Z.; Li, Z.; Yao, Z.; Zhang, J.; Zhang, Z.; Xiang, S. Enhanced intrinsic proton conductivity of metal-organic frameworks by tuning the degree of interpenetration. Cryst. Growth Des. 2018, 18, 3724-3728.

30. Wang, X.; Chen, Z.; Zhao, X.; Yao, T.; Chen, W.; You, R.; Zhao, C.; Wu, G.; Wang, J.; Huang, W.; et al. Regulation of coordination number over single Co sites: Triggering the efficient electroreduction of $\mathrm{CO}_{2}$. Angew. Chem. Int. Ed. 2018, 57, 1944-1948. [CrossRef] 
31. Chen, Y.Z.; Wang, C.; Wu, Z.Y.; Xiong, Y.; Xu, Q.; Yu, S.H.; Jiang, H.L. From bimetallic metal-organic framework to porous carbon: High surface area and multicomponent active dopants for excellent electrocatalysis. Adv. Mater. 2015, 27, 5010-5016. [CrossRef] [PubMed]

32. Zhang, M.; Wu, D.; Ye, Y.; Wu, L.; Yao, Z.; Ma, X.; Wang, L.; Zhang, Z.; Xiang, S. Thermal conversion of MOF@MOF: Synthesis of an N-doped carbon material with excellent ORR performance. ChemPlusChem 2018, 83, 1044-1051. [CrossRef]

33. Sun, X.; Lu, L.; Zhu, Q.; Wu, C.; Yang, D.; Chen, C.; Han, B. MoP nanoparticles supported on indium-doped porous carbon: Outstanding catalysts for highly efficient $\mathrm{CO}_{2}$ electroreduction. Angew. Chem. Int. Ed. 2018, 57, 2427-2431. [CrossRef] [PubMed]

34. Saravanan, M.; Nair, S.V.; Rai, A.K. Low temperature synthesis of carbon-wrapped CuO synthesized without using a conventional carbon source for Li ion Battery Application. Phys. E Low-Dimens. Syst. Nanostruct. 2017, 94, 113-117. [CrossRef]

35. Choi, K.J.; Jang, H.W. One-dimensional oxide nanostructures as gas-sensing materials: Review and issues. Sensors 2010, 10, 4083-4099. [CrossRef] [PubMed]

36. Rahman, M.; Ahammad, A.J.; Jin, J.H.; Ahn, S.J.; Lee, J.J. A comprehensive review of glucose biosensors based on nanostructured metal-oxides. Sensors 2010, 10, 4855-4886. [CrossRef] [PubMed]

37. Prathap, M.A.; Kaur, B.; Srivastava, R. Hydrothermal synthesis of $\mathrm{CuO}$ micro-/nanostructures and their applications in the oxidative degradation of methylene blue and non-enzymatic sensing of glucose $/ \mathrm{H}_{2} \mathrm{O}_{2}$. J. Colloid Interface Sci. 2012, 370, 144-154. [CrossRef]

38. Yang, Y.J.; Li, W.; Wu, X. Copper sulfide reduced graphene oxide nanocomposite for detection of hydrazine and hydrogen peroxide at low potential in neutral medium. Electrochim. Acta 2014, 123, 260-267. [CrossRef]

(C) 2019 by the authors. Licensee MDPI, Basel, Switzerland. This article is an open access article distributed under the terms and conditions of the Creative Commons Attribution (CC BY) license (http://creativecommons.org/licenses/by/4.0/). 